\section{Rapid changes in lifestyle make increased physical activity a priority for the Americas}

\author{
Enrique Jacoby, ${ }^{1}$ Fiona Bull, ${ }^{2}$ \\ and Andrea Neiman ${ }^{3}$
}

The health benefits of regular participation in sports and aerobic fitness have been well recognized for more than 30 years. However, over the past decade new scientific evidence has shown that physical activity need not be strenuous to be beneficial to health. In fact, 30 minutes of moderate-intensity physical activity every day or on most days of the week provides important health benefits. This modest but regular amount of activity can greatly reduce or prevent the risk of cardiovascular disease, type 2 diabetes, osteoporosis, colon cancer, and breast cancer. Regular, moderate physical activity, including daily activities such as climbing stairs, brisk walking, and biking, can reduce stress, alleviate depression and anxiety, enhance self-esteem, and increase mental alertness (1). Moreover, school-age children who are regularly active demonstrate enhanced school performance and a better sense of personal and social responsibility than those who are more sedentary (2).

Most of those health benefits have been widely publicized and to some extent enjoy popular recognition. Nevertheless, sedentary lifestyles are predominant in most urban areas worldwide. Indeed, inactivity constitutes an important risk factor behind the epidemic rates of noncommunicable diseases (NCDs). In its 2002 World Health Report (3) the World Health Organization (WHO) reported that $76 \%$ of all deaths in the Americas in the year 2000 were due to NCDs, a proportion similar to that found in the developed regions of Europe (86\%) and the Western Pacific (75\%). In that same year in Latin America alone there were an estimated 119000 deaths due to inactive lifestyles.

Latin America and the Caribbean have become the most urbanized region in the developing world, with over $60 \%$ of the population residing in urban centers. This rapid urban population growth has outpaced the development of social and physical infrastructure, employment, health services, and housing. Together, these various trends have contributed to inadequate public transportation systems, increased traffic congestion and environmental pollution, decreased activity levels in both work and leisure time, and changes to the physical and social urban landscape.

Data from 24 countries in the Region of the Americas indicate that over half the population are inactive, that is, not performing the minimum recommended 30 minutes of moderate-intensity activity on at least 5 days of the week (3). In several of the countries of the Americas the proportion of the population at risk due to inactive lifestyles is close to $60 \%$. This situation may be especially critical among persons 60 and older. These persons make up the fastest growing segment of the population in Latin America and the Caribbean, with a growth rate that is 3.5 times that of the population overall. In addition, these older persons have the highest prevalence of NCDs. For this large and growing population with decreased mobility and other health concerns, environments that support a physically active lifestyle and greater access to public transportation are becoming increasingly important.

\section{IMPROVED SURVEILLANCE AND MORE DATA ARE URGENTLY NEEDED}

In most parts of the world little or nothing has been done to monitor trends in physical activity. Just 31 of the 191 WHO Member States had physical activity data that were suitable for use in the recent comparative risk assessment project that formed the basis of the risk factor analyses for the 2002 
World Health Report. Data were available for only 4 countries in Latin America. Unfortunately, if there are not adequate data to inform practice and policy, then physical inactivity will continue to be regarded as an issue of sports and recreation rather than a major public health risk factor requiring concerted action from all sectors of government and society at large.

Great progress has been made in developing a simple instrument to assess physical activity and to provide information for use in population health surveillance systems. The International Physical Activity Questionnaire (http://www.ipaq.ki.se/) has been tested in 14 countries and is currently in use in several regional health promotion networks. It is also the core instrument in a large demonstration project involving 24 countries across all six WHO regions that is intended to collect a global sample of nationally representative data on physical inactivity. While there may never be the perfect set of questions to capture all the complexities of physical inactivity, the use of a standard measure allows comparisons within one country, between neighboring countries, and at a regional and global level. When comparable data exist, it is easier to share the experiences and lessons learned from such efforts as policy implementation, mass media campaigns, promotion of walking and cycling for transport, and other intersectoral actions that create environments encouraging active lifestyles.

\section{PROGRESS IN GATHERING DATA ON LATIN AMERICA}

This issue of the Revista Panamericana de Salud Pública/Pan American Journal of Public Health presents landmark reports on physical activity from four countries in the Latin America. The studies provide an initial glimpse into the magnitude of inactivity in Brazil (4), Chile (5), Mexico (6), and Peru (7). Overall, these articles report that more than two thirds of the population do not meet the recommended levels of physical activity sufficient to gain health benefits. This high level of inactivity and the resulting health risks are particularly worrisome in the face of rapid, broad changes in urban lifestyles that favor convenience and comfort in every domain of our lives: at work, in household tasks, in transportation, and in leisure-time activities.

Some specific sociodemographic factors associated with sports and exercise participation are worth mentioning. The studies in Brazil (4), Chile (5), and Peru (7) show that there is less participation in physical activities by women in comparison to men as well as declining rates of participation with age, a finding that is consistent with many studies in other parts of the world. Also as in other areas of the world, the Revista/Journal articles on Brazil (4) and Chile (5) (and less so the one on Peru (7)) show that people in higher income brackets are more likely to engage in physical activity. These findings highlight the need to keep an eye on the equity aspects of promoting sports and other fitness activities.

This issue of the Revista/Journal also presents two exemplary examples of physical activity promotion in the Americas: Agita São Paulo in Brazil (8) and the VIDA CHILE program (5). Starting as a local, grassroots initiative, the Agita São Paulo Program alliance went on to become an inclusive, statewide coalition of public and private institutions. The contagious effect of Agita São Paulo has already "infected" the rest of Brazil as well as many other countries in the Americas. This notable success makes it worth reviewing the detailed account by Sandra Matsudo et al. (8) of the Program's structure, strategies, and evaluation efforts.

Salinas and Vio (5) describe the VIDA CHILE program and highlight the broad consensual efforts among more than two dozen institutions working together for improved health and quality of life for all Chileans. This 
unique, intersectoral collaboration has addressed a wide range of important issues, including creating guidelines for physical activity at the population level, training personnel, fostering school programs, and improving public spaces for recreation.

As the developing countries in the Region of the Americas continue their rapid economic and demographic transition, chronic health conditions continue to grow in importance, and broader prevention efforts become even more essential. Physical inactivity now ranks among the five most important causes of ill health and premature death in the Americas. Reversing current trends will require a wide range of strategies, some of them well beyond the traditional realm of public health. Sustainable program activities aimed at the individual and at entire communities are needed in combination with initiatives to improve the environmental support for active lifestyles.

The physical and social environment plays an enormous role in influencing levels of activity: If there are no alternatives, then car ownership, urban sprawl, and inadequate public transportation in Latin America and the Caribbean will follow the same trends seen in North America over the past two decades, fueling epidemics of inactivity, obesity, and diabetes and other NCDs. With no access to safe outside areas for recreation and with many school systems downplaying physical education, children are likely to spend more time in sedentary pursuits such as watching television and playing video games.

On the other hand, there can be a synergy between reversing these negative patterns and achieving objectives in public health and in other areas, including pollution control, street safety, mental health, transportation, recreation, and city governance. In the coming years, bringing together all those different interests will probably remain one of the major challenges for public health professionals in the Americas.

\section{REFERENCES}

1. Pate RR, Pratt M, Blair SN, Haskell WL, Macera CA, Bouchard C, et al. Physical activity and public health. A recommendation from the Centers for Disease Control and Prevention and the American College of Sports Medicine. JAMA 1995;273(5):402-407.

2. Jensen E. Learning with the body in mind. San Diego: Brain Store; 2000.

3. World Health Organization. 2002 world health report: reducing risks, promoting healthy life. Geneva: WHO; 2002.

4. Monteiro CA, Conde WL, Matsudo SM, Matsudo VR, Bonseñor IM, Lotufo PA. A descriptive epidemiology of leisure-time physical activity in Brazil, 1996-1997. Rev Panam Salud Publica 2003;14(4):246-254

5. Salinas J, Vio F. Promoción de salud y actividad física en Chile: política prioritaria. Rev Panam Salud Publica 2003;14(4):281-288.

6. Hernández B, Haene J de, Barquera S, Monterrubio E, Rivera J, Shamah T, et al. Factores asociados con la actividad física en mujeres mexicanas en edad reproductiva. Rev Panam Salud Publica 2003;14(4):235-245.

7. Seclén-Palacín JA, Jacoby ER. Factores sociodemográficos y ambientales asociados con la actividad física deportiva en la población urbana del Perú. Rev Panam Salud Publica 2003;14(4):255-264.

8. Matsudo SM, Matsudo VR, Araujo TL, Andrade DR, Andrade EL, Oliveira LC de, et al. The Agita São Paulo Program as a model for using physical activity to promote health. Rev Panam Salud Publica 2003;14(4):265-272. 